\title{
STAGED CAROTID ANGIOPLASTY TO PREVENT CEREBRAL HYPERPERFUSION SYNDROME.
}

A. Barragán Prieto', M. Duque Holguera1, V. Romero Cantero', S. Moreno Pulido1, J.C. Portilla Cuenca ${ }^{1}$, A. Serrano Cabrera', S. Romani' ${ }^{2}$, S. Moyano Calvente ${ }^{2}$, I. Casado Naranjo'.

${ }^{1}$ Hospital San Pedro De Alcántara, Neurología, Cáceres, Spain.

${ }^{2}$ Hospital San Pedro De Alcántara, Neurorradiología intervencionista, Cáceres, Spain.

\section{Background and Aims}

Cerebral hyperperfusion syndrome (CHS)

is one of the most dangerous complications of carotid revascularization treatment. Exhausted cerebral vasoreactivity (CVR) has been associated with an increased risk of CHS. Staged angioplasty could be a therapeutic alternative, with a balloon dilation in a first stage and stent placement in a second time. Our objective is to evaluate the safety of endovascular treatment in two stages in patients at high risk of $\mathrm{CHS}$.

\section{Method}

Description of a serie of cases.

\section{Results}

\begin{tabular}{|lcccc|}
\hline Sex & Pt. 1 & Pt. 2 & Pt. 3 & Pt. 4 \\
\hline Age & Male & Male & Male & Male \\
\hline Stroke & 53 & 50 & 73 & 72 \\
\hline NIHSS on admission & Right & Left & Left & Right \\
\hline NIHSS at discharge & 20 & 21 & 14 & 18 \\
\hline \% of symtomatic stenosis & 15 & 6 & 0 & 4 \\
\hline Cerebral Vasoreactivity & $95 \%$ & $90 \%$ & $99 \%$ & $99 \%$ \\
\hline Angioplasty day & $\downarrow$ & $\downarrow$ & Absent & $\downarrow$ \\
\hline Stenting day & 29 & 15 & 5 & 46 \\
\hline Use of distal filter & 60 & 45 & 32 & 68 \\
\hline Postprocedure complication & Yes & Yes & Yes & Yes \\
\hline
\end{tabular}

Table. Summary of cases
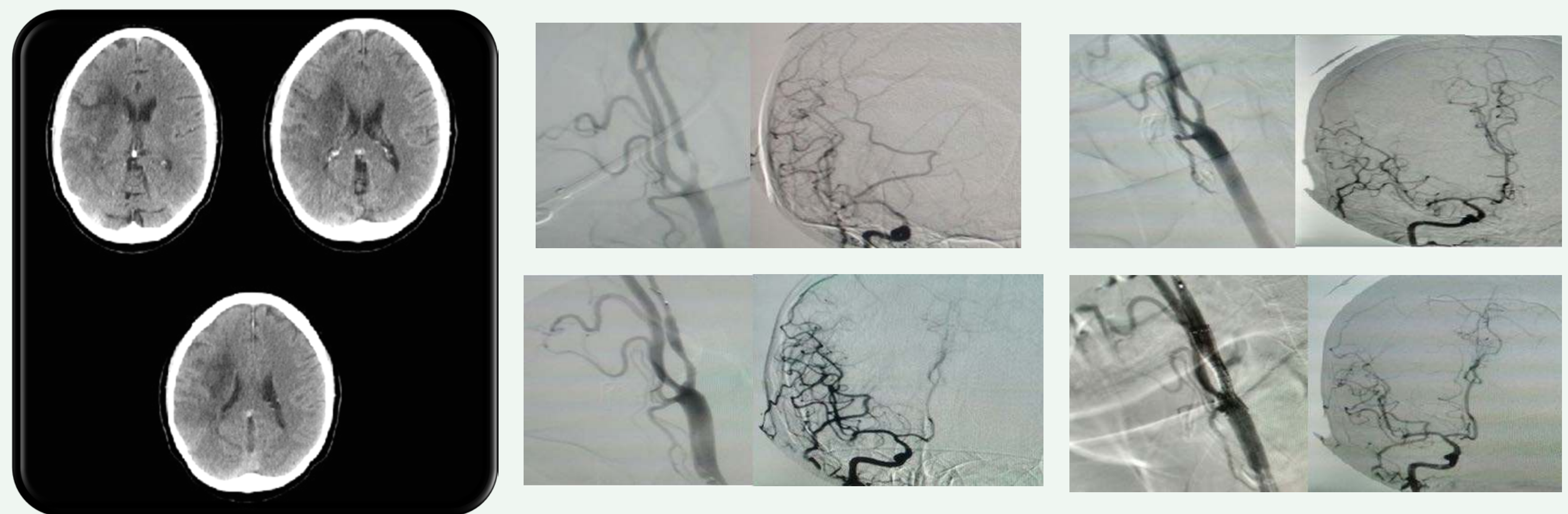

\section{Conclusion}

In our experience, staged angioplasty is a safe technique in patients at high risk of CHS.

\section{Keywords}

Staged angioplasty; Hyperperfusion syndrome; Secundary Prevention 